\title{
¿Es posible la reparación integral a víctimas de trata de personas mediante una acción civil in forma pauperis?
}

\author{
Is it Possible to Provide Compensation to Victims of \\ Human Trafficking through a Civil Action in forma \\ pauperis? \\ É possível uma reparação integral para as vítimas \\ de tráfico de pessoas por meio de uma ação civil \\ in forma pauperis?
}

\section{Daniela Sodini*}

Fecha de recepción: 21 de abril de 2021

Fecha de aprobación: 22 de julio de 2021

Doi: $h$ ttps://doi.org/10.12804/revistas.urosario.edu.co/anidip/a.11423

Para citar este artículo: Sodini, D. ¿Es posible la reparación integral a
víctimas de trata de personas mediante una acción civil in forma pau-
peris?, ANIDIP, 9, 1-28. Doi: https://doi.orģ/10.12804/revistas.urosario.
edu.co/anidip/a.11423

\section{Resumen}

La trata de personas supone una grave violación de los derechos humanos fundamentales de sus sobrevivientes. Aunque la persecución penal de los autores y su eventual condena permita a la víctima librarse del sometimiento que padecía, esto no le asegurará la reparación integral del daño sufrido por el delito. Para obtenerla, el proceso penal argentino exige asumir el rol de actor civil o, de lo contrario, se rechazará cualquier pretensión resarcitoria. El principal inconveniente es que los requisitos para reclamar la indemnización para una víctima en situación de vulnerabilidad significarán la imposibilidad de llevar adelante cualquier reclamo al no contemplar la posición desventajosa en que se encuentra la víctima de trata para litigar contra quien poco tiempo antes era su explotador. Esto entra en colisión con 
los compromisos internacionales en materia de derechos humanos asumidos por Argentina de garantizar el acceso a la justicia y la reparación económica de quienes se encuentran en situación de vulnerabilidad. Esta investigación indagará sobre la posibilidad de que el Estado otorgue un acceso integral a la justicia sin someter a la víctima a exigencias procesales para alcanzar la reparación económica que signifiquen una nueva victimización o impidan la satisfacción de sus derechos.

Palabras clave: trata de personas; reparación integral; acceso a la justicia; vulnerabilidad; derechos humanos.

\begin{abstract}
Human trafficking is a serious violation of the fundamental human rights of its survivors, and although the criminal prosecution of its perpetrators and their eventual conviction will allow the victim to free herself/himself from the subjugation suffered, it will not ensure full reparation for the harm suffered due to the crime. To obtain it, the Argentinean criminal process requires the victim to assume the role of civil plaintiff. Otherwise, any claim for compensation will be rejected. The main drawback is that the requirements for claiming compensation for a victim in a situation of vulnerability will make it impossible to pursue any claim as it does not consider the disadvantaged position in which the victim of trafficking finds herself/himself to litigate against the person who shortly before was her/his exploiter. This clashes with Argentina's international human rights commitments to guarantee access to justice and economic reparation for those in vulnerable situations. This research will investigate the possibility of the state granting comprehensive access to justice without subjecting the victim to procedural requirements for financial reparation, which would result in new victimization or prevent the fulfillment of their rights.
\end{abstract}

Keywords: Human trafficking; compensation; access to justice; vulnerability; human rights.

\title{
Resumo
}

O tráfico de pessoas é uma grave violação dos direitos humanos fundamentais de seus sobreviventes e, embora o processo criminal dos perpetradores e a eventual condenação permitam à vítima se libertar da sujeição que sofreu, não garantirá a reparação integral dos danos sofridos pelo crime. Para obtê-lo, o processo penal argentino exige que se assuma o papel de ator civil ou, caso contrário, qualquer pedido de indenização será rejeitado. A principal desvantagem é que os requisitos para reclamar indenização para uma vítima em situação de vulnerabilidade significará a impossibilidade de realizar qualquer reclamação não considerando 
a posição desvantajosa de vítima de tráfico para litigar contra quem pouco tempo antes era o seu explorador. Isso se choca com os compromissos internacionais de direitos humanos assumidos pela Argentina para garantir o acesso à justiça e a reparação econômica às pessoas em situação de vulnerabilidade. Este trabalho investigará a possibilidade de o Estado conceder acesso integral à justiça, sem submeter a vítima a demandas processuais para obter uma reparação econômica que represente uma nova vitimização, ou que impeça o cumprimento de seus direitos.

Palavras-chave: tráfico de pessoas; reparação integral; acesso à justiça;

vulnerabilidade; direitos humanos.

\section{Introducción}

El delito de trata de personas supone una grave violación de los derechos humanos fundamentales de la víctima (ACNUDH, 2014) porque niega su condición de persona y la asimila a un objeto comercializable en el mercado de bienes y servicios. La persecución penal de los autores y eventual condena, si bien permitirá a la víctima librarse del sometimiento que padecía, no le asegurará la reparación integral del daño sufrido por el delito, pues será necesario solicitar una reparación económica por medio de una indemnización. En ese sentido, la Corte Interamericana de Derechos Humanos (Corte IDH) ha reconocido el deber de satisfacer dicho derecho por parte de los Estados y sostenido en reiterada jurisprudencia: "es un principio de derecho internacional que toda violación de una obligación internacional que haya producido un daño comporta el deber de repararlo adecuadamente" (Villagrán Morales y otros [Caso de los "Niños de la Calle”] c. Guatemala, 2001, párr. 59).

Precisamente, todo daño provocado por el delito tiene como consecuencia la obligación de reparar el perjuicio sufrido, pero ante una grave violación de derechos humanos y frente a los sobrevivientes ${ }^{1}$ en condición de vulnerabilidad, la reparación se vuelve impostergable. Si bien esta obligación recae en la persona condenada o en quien se hubiere beneficiado económicamente de la explotación, lo cierto es que si el derecho interno no habilita un acceso real y efectivo a la justicia que incluya la reparación económica ante el interés expreso de obtenerla de la persona afectada por el delito, esta situación podría significar una responsabilidad internacional para el Estado.

A pesar de que la Argentina se ha comprometido internacionalmente a garantizar el acceso a la justicia y a generar las condiciones para asegurar la reparación económica a víctimas en situación de vulnerabilidad, tanto en instrumentos internacionales

1 A lo larơo de este trabajo, se utilizarán indistintamente los términos de víctimas y sobrevivientes, aunque sea preferible este último término en virtud de la connotación de reparación y resiliencia que conlleva (onu Mujeres, s. f.). 
de soft law como en tratados internacionales de derechos humanos con jerarquía constitucional, el Código Procesal Penal de la Nación (CPPN) exige la constitución en actor civil o, de lo contrario, se rechazará el otorgamiento de cualquier reparación. Esto es lo que ha ocurrido cuando, ante propuestas concretas, los tribunales rechazaron acuerdos preparatorios argumentando que los damnificados no se habían constituido en la causa como "actores civiles" (Cruz Nina, Julio César; Huarina Chambi, Silvia s/ trata de personas, 2016, [Cruz Nina]).

En un escenario ideal, quien sufrió un daño a causa de un delito debería encarar un reclamo resarcitorio por sus propios medios o evitando la subrogación de la acción. Sin embargo, en la trata de personas y delitos conexos se da una situación particular que dificulta cualquier posibilidad real de realizarlo. En ese sentido, es posible pensar en una solución que recoja una visión restaurativa que ponga el foco en la compensación del daño a la víctima, que haga responsable a los declarados culpables (UNODC, 2006, p. 6).

Las exigencias para la interposición de una demanda resarcitoria resultan incompatibles con un sobreviviente vulnerado, lo que podría significar la violación de derechos de raigambre constitucional por una norma que los reglamenta y no está diseñada para contemplar la posición desventajosa en que se encuentra la víctima de trata, por ejemplo, para litigar contra quien poco tiempo antes era su explotador. Como se abordará más adelante, quienes han sobrevivido a delitos tan aberrantes como la explotación de personas atraviesan un largo proceso con miras a su recuperación y, en la mayoría de los casos, recién se autoperciben como víctimas luego de avanzado el proceso o de la condena de los responsables. Esta circunstancia se suma a las numerosas adversidades que deben pasar y que conspiran contra las reales posibilidades de encarar una demanda civil para obtener una compensación económica. Si se parte de postulados estrictamente retribucionistas, el rol central del proceso penal es la identificación y sanción de los responsables del delito. No obstante, a partir de la introducción de una visión más restaurativa (tal como se podría advertir, por ejemplo, con la sanción de la Ley 27.372), podría entenderse que poco a poco se va adoptando una perspectiva que otorga a la víctima un rol más importante en el proceso que no la limita a ser solo testigo de los hechos que se pretenden esclarecer y que se orienta a reparar el daño sufrido por el delito (Gutiérrez Rodríguez, 2017, p. 48).

Por ello, lo que aquí se propone es flexibilizar los requisitos para interponer una acción civil resarcitoria a fin de cumplir con los derechos de acceso a la justicia y reparación integral. Este planteamiento no rechaza el acompañamiento y asistencia que las personas sobrevivientes a estos delitos requieren, sino que reconoce 
las limitaciones de este tipo de ayuda que se advierte insuficiente al momento de reclamar un resarcimiento frente a su explotador.

Aquí juega un rol especial el acceso a la justicia (o jurisdicción) que, en palabras de Pozzo (2012), "constituye un 'derecho puente' para la obtención del reconocimiento ante la justicia de los otros derechos fundamentales que posee todo el ser humano por su condición de tal" (p. 161). Resultaría estéril consagrar derechos si luego la regulación del proceso constituye un verdadero obstáculo para su consecución.

Así planteado, hasta podría acarrear la responsabilidad internacional de la Argentina, por cuanto el Estado debe garantizar un efectivo acceso a la justicia (Convención Americana sobre Derechos Humanos [CADH], artículo 8; Pacto Internacional de Derechos Civiles y Políticos [PIDCP], artículo 14), pues de lo contrario, violaría el principio de igualdad y defensa en juicio reconocidos tanto en la Constitución Nacional ([CN] artículos 16 y 18), como en tratados internacionales.

Si bien la reparación incluye distintas modalidades, la propuesta que aquí se realiza se refiere únicamente a la económica y las posibilidades para acceder a ella. Por esa razón, no se abordarán reparaciones simbólicas, en especial atendiendo a la vocación transformadora de las reparaciones en el derecho internacional, como podrían ser aquellas de orden simbólico o atinentes a erradicar situaciones de discriminación estructural - tal como ha sido expuesto en el caso González y otras [Campo Algodonero] c. México (párr. 450) - . Lo que se pretende en este estudio es asegurar un acceso a la reparación económica como integrante del derecho al recurso y acceso a la justicia.

\section{Derecho a la reparación en el contexto internacional}

El derecho a reparación está ampliamente reconocido en diversos tratados internacionales y regionales de derechos humanos. La Declaración Universal de Derechos Humanos, en su artículo 8, establece el derecho de toda persona a un recurso efectivo. Por su parte, el PIDCP determina que los Estados deberán garantizar que toda persona, ante la violación de un derecho, pueda interponer un recurso efectivo (artículo 2.3). En el mismo sentido, lo hacen la Convención contra la Tortura y otros Tratos o Penas Crueles, Inhumanos o Degradantes (artículo 13), el Convenio Europeo para la Protección de los Derechos Humanos y de las Libertades Fundamentales (artículo 13), la Carta Africana de Derechos Humanos y de los Pueblos (artículo 7. 1. a), la Carta Árabe de Derechos Humanos (artículo 9) y el Estatuto de la Corte Penal Internacional (CPI), por mencionar algunos.

Los Principios y directrices básicos sobre el derecho de las victimas de violaciones manifiestas de las normas internacionales de derechos humanos y de violaciones graves 
del derecho internacional humanitario a interponer recursos y obtener reparaciones (Principios sobre el derecho a obtener reparaciones) ofrecen mecanismos para que los Estados cumplan con las obligaciones internacionales contenidas en los tratados de derechos humanos y de derecho internacional humanitario, expresados en principios y directrices, tal como su nombre indica. La primera obligación consiste en respetar, asegurar y aplicar las normas de derecho internacional que incluyen el deber de proporcionar a las víctimas recursos eficaces, entre los que encontramos la reparación (artículos 1 y 3). El artículo 11 establece como derechos de las víctimas contar con un acceso igual y efectivo a la justicia y a la reparación adecuada, efectiva y rápida del daño sufrido. Sobre este último derecho, el documento explica que la reparación debe ser proporcional a la gravedad de las violaciones y que la parte responsable, ya sea el Estado o un tercero particular, deberá conceder la reparación (o indemnizar al Estado si este reparó a la víctima). Además, el documento determina como parte de las obligaciones de los Estados establecer procedimientos para que tanto individuos como grupos de víctimas puedan presentar demandas de reparación y obtenerla (artículo 13), como medidas para proporcionar un adecuado derecho de acceso a la justicia.

Por su parte, la relatora especial sobre la trata de personas entiende que el derecho a la reparación no se limita al derecho sustantivo, sino que también incluye un "conjunto de derechos procesales necesarios para facilitar el acceso a una reparación" (Ezeilo, 2011, 7). Es decir, en la medida en que la ley procesal no permita una posibilidad real de obtener una reparación, esta no se verá satisfecha a la luz de la normativa internacional de derechos humanos.

La obligación de proporcionar mecanismos efectivos a las víctimas de violaciones de derechos humanos para obtener reparación por el daño sufrido ha sido ratificada en distintas ocasiones por la Asamblea General de las Naciones Unidas (AGNU), el Consejo de Derechos Humanos y otros organismos de derechos humanos (ACNUDH, 2014, p. 35).

Por otro lado, el compromiso estatal frente a ellas fue compelido por la onU en los principios adoptados en la Declaración sobre los Principios Fundamentales de Justicia para las Víctimas de Delitos y del Abuso de Poder, en la que se reconoce a las víctimas el derecho de acceso a los mecanismos de justicia y a una pronta reparación (principio 4) para lo que los Estados deberán establecer y reforzar los mecanismos judiciales y administrativos que permitan la obtención de "reparación mediante procedimientos oficiales u oficiosos que sean expeditos, justos, poco costosos y accesibles" (principio 5). También postula que los procedimientos judiciales deben adecuarse a las necesidades de las víctimas a fin de que, entre 
otros, se eviten demoras innecesarias en la ejecución de las causas e indemnizaciones (principio 6).

Asimismo, en el documento elaborado por el Alto Comisionado de Naciones Unidas para los Derechos Humanos, Principios y directrices recomendados sobre los derechos humanos y la trata de personas (ECOsOc, 2002), encontramos el principio nueve que recomienda a los Estados proporcionar asistencia jurídica y de otra índole mientras duren las acciones penales y civiles. En el documento se explica que la reparación plena y efectiva se dará de las siguientes formas: restitución, indemnización, rehabilitación, satisfacción y garantías de no repetición. Con relación a la restitución, señala que significará, siempre que sea posible, "devolver a la víctima a la situación anterior a la violación manifiesta de las normas internacionales de derechos humanos o la violación grave del derecho internacional humanitario" (artículo 19). La indemnización habrá de concederse "por todos los perjuicios económicamente evaluables que sean consecuencia de violaciones manifiestas de las normas internacionales de derechos humanos o de violaciones graves del derecho internacional humanitario" (artículo 20).

En el ámbito americano, la CADH brinda el fundamento jurídico general para el sistema de reparaciones por violaciones de derechos humanos. Su artículo 63. 1 establece que, ante la violación de un derecho o libertad protegido en dicho instrumento, se garantizará al lesionado el goce de su derecho o libertad conculcados, si ello fuera procedente, se dispondrá que se reparen las consecuencias de la medida o situación que ha configurado la vulneración de esos derechos y el pago de una indemnización.

Argentina adoptó una postura más comprometida al aprobar la Convención de Naciones Unidas contra la Delincuencia Organizada Trasnacional (CNUDOT), con lo que reforzó aquellos principios internacionales y asumió el compromiso de dictar los procedimientos adecuados que permitan a las víctimas de los delitos comprendidos en el tratado obtener una indemnización y restitución (artículo 25. 2).

Para el caso de trata y explotación de personas, distintos documentos e instrumentos jurídicos reconocen el derecho a la reparación económica. Por ejemplo, el artículo 6. 6 del Protocolo de Palermo, que complementa la CNUDOT, promueve que cada Estado parte prevea en su ordenamiento medidas que permitan a las víctimas obtener indemnización por los daños sufridos. Si bien el lenguaje utilizado por el Protocolo de Palermo no pareciera ser imperativo, lo cierto es que teniendo en cuenta el carácter progresivo de los derechos humanos y el principio de interpretación pro persona, debe entenderse como una obligación de garantizar la reparación de los daños sufridos como consecuencia del delito para todos los Estados 
parte. Esto corresponde a que sea entendido en el sentido de que el Estado debe asegurar los mecanismos necesarios para conseguirla, posición que se ve respaldada por la decisión de la Corte IDH en el caso Trabajadores de la Hacienda Brasil Verde c. Brasil de 2016, sobre el que ampliaré más adelante.

En esa línea, y con relación a los bienes decomisados por ser producto o provecho del delito o instrumento, ${ }^{2}$ el artículo 14.2 de la CNUDOT establece la prioridad a la entrega del producto del delito o de los bienes decomisados al Estado requirente para cubrir las indemnizaciones o devolver los activos a sus propietarios legítimos, es decir, establece la preferencia de la restitución por sobre el decomiso o cualquier otro derecho que se pretenda hacer valer sobre los bienes.

En nuestra región, con la suscripción de la Convención de Belem do Pará, los Estados parte se comprometieron no solo a condenar la trata de personas como una manifestación de la violencia contra la mujer, sino que también asumieron la responsabilidad de "establecer los mecanismos judiciales y administrativos necesarios para asegurar que la mujer objeto de violencia tenga acceso efectivo a resarcimiento, reparación del daño u otros medios de compensación justos y eficaces" (artículo 7. g).

En Europa, encontramos el Convenio del Consejo de Europa sobre la Trata de Seres Humanos que reconoce a las víctimas el derecho a recibir una compensación económica por parte de los tratantes y, en ese sentido, exige a los Estados adoptar las medidas necesarias para garantizar las indemnizaciones (artículo 15).

Ahora bien, que normativamente exista la posibilidad de obtener reparación económica por el delito no implica su obtención, especialmente cuando se trata de violaciones a derechos humanos y las víctimas son vulnerables. La experiencia indica que quienes han sido subyugados al poder del tratante, restringiéndoseles su libertad, autonomía y poder de decisión nunca iniciarán una pretensión resarcitoria por sí solas. No es fácil liberarse del sometimiento (que puede persistir después de la liberación física), lo que demuestra la desigualdad de fuerzas entre una y otra parte.

Es importante tener presente que además de la barrera económica y los problemas que puedan suscitarse en torno a su seguridad, en muchos casos la víctima debe concebirse como sujeto de derechos. Muchas veces ni siquiera se autoperciben como víctimas y, tal como afirman Requena Espada et al. (2012, p. 6), tampoco son conscientes de la vulneración de los derechos humanos que padecieron ni terminan de comprender la magnitud de la afectación de sus derechos. Aquí adquieren importancia

2 Sobre el decomiso de activos que sirvieron para el delito o son producto o provecho de este, ver el capítulo 6. 2. 
las Guías de Santiago sobre protección de víctimas-testigos ${ }^{3}$ al recomendar que la intervención de la víctima en el proceso no suponga un costo que no pueda afrontar o que le impida intervenir en él (artículo 5. d). Es decir, corresponde al Estado (en este caso representado por los operadores jurídicos, ante la carencia de una norma procesal específica) disponer de los medios necesarios para que las reivindicaciones que la víctima pueda hacer durante la sustanciación del juicio penal no se vean limitadas por la imposibilidad de afrontar los costos de dicha participación o porque esta implique asumir roles que dilaten la satisfacción de sus derechos. La evidente asimetría entre víctima y victimario en estos casos dificulta cualquier posibilidad real de que el damnificado asuma un rol activo para obtener una reparación.

En este escenario, un procedimiento que no contemple las características especiales de una víctima en condición de vulnerabilidad atentará directamente contra el derecho de acceso a la justicia y el principio de igualdad. De nada servirá que se reconozca a la víctima un derecho a la reparación si no puede acceder de manera efectiva al sistema de justicia para obtenerla. Por esa razón entiendo que desde el Estado deben adoptarse las medidas necesarias para que la reparación del daño sufrido no se vea entorpecida por el hecho de cumplir con el procedimiento vigente, sin ningún tipo de miramientos, con un régimen más cercano a la burocracia que a un buen servicio de justicia.

La Corte IDH se ha expresado no solo sobre el concepto de trata y explotación de personas a la luz de los estándares internacionales, sino que también lo ha hecho sobre el derecho a la reparación económica de las víctimas de esta atroz violación de derechos humanos. Así, por ejemplo, lo manifestó en el caso Trabajadores de Hacienda Brasil Verde, donde también reconoció la responsabilidad estatal por actos de terceros. En este sentido, la Corte IDH entiende que la indemnización es el medio más adecuado para reparar los daños ocurridos a partir de la violación de los derechos humanos y afirmó en el caso Velásquez Rodríguez:

la reparación del daño ocasionado por la infracción de una obligación internacional consiste en la plena restitución (restitutio in integrum), lo que incluye el restablecimiento de la situación al estado anterior y la reparación de las consecuencias que la infracción produjo y el pago de una indemnización como compensación por los daños patrimoniales y extrapatrimoniales incluyendo el daño moral (párr. 26).

3 Son recomendaciones concretas dirigidas a los operadores jurídicos, especialmente a los fiscales, aprobadas en la XVI Asamblea General Ordinaria de la Asociación Ibero de Ministerios Públicos (AIAMP), el 9 y 10 de julio de 2008. El Ministerio Público Fiscal (MPF) argentino aprobó el documento mediante Resolución PGN $n^{\circ} 174 / 08$. 
Como presupuesto para dicha reparación, la Corte IDH consideró que el Estado tiene la obligación no solo de prevenir las violaciones de los derechos humanos, sino también de investigarlas seriamente, imponer sanciones y "asegurar a las víctimas una adecuada reparación" (párr. 174).

En el caso Trabajadores de la Hacienda Brasil Verde c. Brasil, la Corte IDH condenó a Brasil por considerarlo responsable internacionalmente por la violación al derecho de no ser sometido a formas de esclavitud moderna y trata de personas, así como también de la violación de las garantías de debida diligencia, plazo razonable, el derecho a la protección judicial y de acceso a la justicia. La importancia de este fallo radica en que es el primero que la Corte IDH expide sobre esclavitud y trata de personas y donde tuvo la oportunidad de desarrollar y actualizar nociones sobre estos delitos.

La Corte IDH ordenó a Brasil retomar las investigaciones sobre el caso y declaró la imprescriptibilidad de los delitos de esclavitud y formas análogas y la reparación a las víctimas, ya que el proceso no había ofrecido un "mecanismo de reparación para las víctimas". Además, dispuso la reparación económica de las personas sobrevivientes, rescatadas en 2000 y 1997 (párrs. 406, 413 y 445).

Respecto de la acción civil presentada, que terminó mediante conciliación, concluyó que no había tomado en consideración la gravedad de los hechos denunciados ni la necesidad de reparación de los sobrevivientes. Entendió que esta situación se tradujo en una "denegación de justicia en perjuicio de las víctimas", pues el Estado no les proveyó de "un recurso efectivo a través de las autoridades competentes, que tutelara sus derechos humanos contra los actos que los vulneraron" (párr. 404). En esto radica la trascendencia del caso, pues la Corte IDH consideró responsable a Brasil por no haber ofrecido un mecanismo de reparación para los sobrevivientes y estimó que el Estado tenía una responsabilidad mayor de proveer un recurso sencillo y efectivo para la protección de sus derechos, incluida su reparación económica, en atención a la situación de vulnerabilidad en que se hallaban.

\section{La reparación en el Código Penal argentino}

Respecto de la reparación de perjuicios en el derecho penal argentino, el artículo 29 del Código Penal (CP) dispone que la sentencia podrá ordenar la indemnización del daño moral y material, la restitución de la cosa obtenida por el delito y el pago de costas. Seguidamente, establece que la obligación de indemnizar es preferente a cualquier otra que el condenado contrajere con posterioridad a la comisión del delito y determina el orden de preferencia para la satisfacción de las responsabilidades pecuniarias para el caso en que los bienes no sean suficientes. De esa manera, dispone que, en primer lugar, se cancelará la indemnización de daños y perjuicios y, luego, será el turno del resarcimiento de los gastos del juicio (CP, artículo 30). 
De todo delito nace la obligación de reparar, lo que puede procurarse a partir de la acción civil. Como las obligaciones de indemnizar son diferentes a la pena que pueda aplicarse al imputado (por ejemplo, multa), las reparaciones pueden hacerse efectivas con bienes del condenado, aunque haya fallecido o de un tercero, pues la reparación posee naturaleza civil (D’Alessio, 2005, p. 179).

Para el caso de trata de personas, la Cámara Federal de Casación Penal (CFCP) profundizó el análisis en torno a las reparaciones económicas y precisó que el artículo 29 CP debe interpretarse bajo el prisma de los tratados internacionales de derechos humanos y el Protocolo de Palermo. Asimismo, como la restitución es una medida accesoria a la condena, puede ordenarse de oficio sin necesidad de que se hubiera iniciado la acción civil y, por consiguiente, el Ministerio Público Federal (MPF) está legitimado a solicitarla en virtud de su función constitucional de defensa de la legalidad (Cruz Nina).

A pesar de que se entiende que la restitución procede de oficio, los tribunales son reticentes a aplicarla y muchas veces pretenden que la persona sobreviviente litigue la acción civil no solo para obtener indemnización, sino también restitución. En el caso de quienes sufrieron el delito de trata de personas, esta situación adquiere una relevancia especial, pues en la práctica significa vedarle cualquier posibilidad de reparar el daño sufrido como consecuencia del delito. Si se repasan los argumentos esgrimidos por los jueces para rechazar ese pedido, se advierte que se basan en una errónea interpretación de la ley vigente, lo que convierte sus decisiones en arbitrarias.

En el siguiente capítulo, detallaré brevemente cómo está regulada la acción civil en el proceso penal. También explicaré los puntos más salientes del primer caso en el que una sobreviviente de trata de personas asumió el rol de actora civil.

\section{La acción civil para obtener la reparación económica por el daño sufrido}

\subsection{La demanda civil en el proceso penal}

El artículo 14 del CPPN establece que la restitución de la cosa obtenida por el delito y la pretensión resarcitoria solo podrán ser ejercidas por el titular de ese derecho subjetivo con patrocinio jurídico. Luego, dispone que para ello debe asumir el rol de actor civil (CPPN, artículo 87), por sí o por mandatarios, lo que se podrá hacer en cualquier momento del proceso hasta la clausura de la instrucción. ${ }^{4}$

\footnotetext{
$4 \quad$ El Código Procesal Penal Federal, Ley 27.063, (cPpF) establece en su artículo 40 la acción civil para la reparación o indemnización de los daños producidos por el delito. En su artículo 42, determina como condición para su ejercicio la constitución de querellante y ejercerla conjuntamente con la acción penal.
} 
A pesar de que la norma procesal es la que determina cómo debe ejercerse la vía reparatoria, esta especie de reglamentación no puede significar un obstáculo para la concreción de esa pretensión y, por tanto, debe garantizársele a la víctima el cobro de la indemnización. Es decir, el derecho a recibir un resarcimiento no debe verse limitado por una deficiente o inadecuada regulación, ante la posibilidad de que ello pueda constituir una revictimización. Con el análisis de la situación de los sobrevivientes de trata y explotación de personas, se advertirá que el procedimiento actualmente vigente para obtener el resarcimiento por el daño causado en la práctica no permite alcanzar dicho objetivo.

\subsection{El caso Alika Kinan}

Este caso fue el primero en el que una víctima de trata demandó a sus tratantes y obtuvo reparación integral por el daño sufrido. El 30 de noviembre de 2016 se condenó a tres personas por el delito de trata agravado por la pluralidad de víctimas, en perjuicio de ocho de ellas (entre las que se encontraba la querellante y actora civil Alika Kinan), que habían sido rescatadas de un local nocturno de la ciudad de Ushuaia. También se hizo lugar a la demanda civil y se condenó a los imputados y a la Municipalidad de Ushuaia a abonar una suma de dinero por concepto de indemnización por daños y perjuicios.

La CFCP confirmó la reparación de daños y perjuicios dispuesta en favor de Alika Kinan, aunque dispuso el reenvío para que se fije un nuevo monto indemnizatorio acorde a lo postulado por la actora civil. Lamentablemente, ella fue la única que obtuvo reparación económica porque se constituyó en actora civil, mientras que las restantes sobrevivientes no lo consiguieron al no haber asumido ese rol.

\section{3. El rol del Ministerio Público de la Defensa}

Este acápite se destinará a realizar una aclaración sobre la función del Ministerio Público de la Defensa de Argentina, que según el artículo 1 de su Ley Orgánica (27.149), tiene como función principal la "defensa y protección de derechos humanos que garantiza el acceso a la justicia y la asistencia jurídica integral, en casos individuales y colectivos". En ese marco, se creó el Programa de Asistencia y Patrocinio para las Víctimas de Delito de Trata de Personas. ${ }^{5}$ Si bien es loable el desempeño de esta dependencia, lo cierto es que su alcance está limitado a los recursos reales de brindar asesoramiento a las víctimas para obtener la reparación integral. Por ejemplo, en el mencionado caso Alika Kinan, fue precisamente este programa el que patrocinó 
su acción civil; no obstante, las otras siete personas damnificadas identificadas en el caso por diferentes razones no lo fueron y quedaron sin reparación económica.

Lo mismo ocurre con la Ley de Derechos y Garantías de las Personas Víctimas de Delitos (Ley 27.372), que creó la figura del Defensor Público de Víctimas. Entre sus funciones se encuentra la de brindar asistencia y patrocinio jurídico a aquellas víctimas que "por la limitación de sus recursos económicos o vulnerabilidad resultara necesaria la intervención del Ministerio Público de la Defensa, en atención a la especial gravedad de los hechos investigados" (artículo 11) y en su caso querellar. Esta última aclaración pareciera limitar la actuación al impulso penal particular sin hacer referencia al ejercicio de la acción civil. ${ }^{6}$

Estas condiciones reducen las posibilidades reales de que las personas sobrevivientes de trata y explotación puedan contar con el patrocinio jurídico necesario para entablar una demanda civil de indemnización, porque además de las limitaciones para contar con la asistencia letrada, también deben recordarse los obstáculos que se les presentan para asumir un rol activo en su reclamo de reparación. Es ilustrativo a ese respecto lo que aconteció en un caso de trata por explotación sexual en el que una de las dos personas que se habían constituido como actoras civiles debió renunciar porque ser actora civil en su demanda resarcitoria le requería un esfuerzo personal, mental y emocional con el que no contaba. ${ }^{7}$

Como puede advertirse, aún cuando quienes fueron objeto de explotación pudieran contar con el asesoramiento letrado para obtener una reparación económica, puede serles difícil lidiar con las vicisitudes del proceso. Esta situación podría no solo conculcar su derecho a la reparación económica, sino también representar un obstáculo a su derecho de acceso a la justicia.

\section{Propuesta de reclamo indemnizatorio para sobrevivientes de trata de personas}

A lo largo del presente trabajo se ha intentado demostrar la particularidad del delito de trata y explotación de personas en cuanto a su doble condición de delito de criminalidad compleja y de grave violación de derechos humanos, lo que impacta irremediablemente en sus víctimas. Entre todas las dificultades que ellas deben atravesar, la posibilidad —o, mejor dicho, la imposibilidad práctica- de entablar una demanda civil para reclamar por los daños y perjuicios sufridos por el delito es una circunstancia que interpela, o tendría que interpelar, a todos los operadores jurídicos.

\footnotetext{
6 Otro dato relevante es que el primer defensor de víctimas prestó juramento recién el 3 de diciembre de 2020, quien tiene competencia territorial en la provincia de Salta.

7 Esta situación se desarrolla en el apartado 4.1.
} 
Por tal motivo, se propone un mecanismo sencillo que permitiría a las víctimas alcanzar una reparación económica integral, hasta tanto la legislación procesal adecúe el procedimiento para obtener las indemnizaciones a dichas víctimas y su condición de vulnerabilidad.

\subsection{El reclamo por indemnización en forma "pauperis" o "in pauperis"}

Si se tiene en cuenta que de las 1500 víctimas identificadas en la justicia federal desde la entrada en vigor de la Ley 26.364 hasta diciembre de 2017 - y las miles de otras que no han sido individualizadas - solo una pudo asumir el rol de actora civil sin que se verificara el inicio de ninguna demanda en el fuero civil, queda claro que la manera en que está regulado el reclamo para la reparación de daños y perjuicios en el proceso penal no es la más apropiada para las víctimas de este delito.

Es más, en 2019 y con los cientos de víctimas que se han agregado a las estadísticas de la Procuraduría de Trata y Explotación de Personas (PROTEX), solo una más ha podido estar en condiciones de entablar una demanda penal y civil para obtener la indemnización por los daños sufridos. Este caso es además esclarecedor sobre el punto que vengo tratando en este trabajo, ya que otra de las víctimas también había asumido dicho rol, pero tuvo que desistir de este. Sobre tal decisión, en la sentencia condenatoria se explicó:

no es posible dejar de lado el desistimiento de querella realizado por la víctima identificada como A1. En esa oportunidad, refirió que lo hacía por motivos personales, que ameritaban dedicar tiempo a cuestiones que la ayuden a "superar los hechos denunciados". Además, explicó que busca priorizar su salud física y mental, agregando que su intervención en estos actuados necesariamente implicaba una participación activa que no deseaba seguir teniendo (Tomasi, Silvio Ángel y otros s/trata de personas, 2019).

Esto demuestra claramente los inconvenientes que atraviesan las víctimas de trata de personas cuando entran en contacto con el sistema penal y por las que sigue representando un obstáculo tener que litigar para conseguir una reparación integral.

La Corte Suprema de la Nación (CSJN) ha dicho que las leyes de fondo no deben ser desvirtuadas por el procedimiento que se utilice para aplicarlas cuando sostuvo que "al determinar la forma de hacer efectiva una convención también especial, la ha rodeado de garantías destinadas a asegurar su inmediata efectividad y sin las cuales se comprometería la existencia misma del derecho que se ejercita" (csjn Fallos, 138:157). Esta cita ofrece la posibilidad de desarrollar una alternativa que, desacralizando las formas, no entorpezca el acceso a la jurisdicción a quienes 
se encuentran en una especial situación de vulnerabilidad que, de ese modo, les permita obtener una reparación económica sin necesidad de cumplir los exigentes requisitos de la acción civil.

Vale la pena destacar el voto del ministro de la csjn, el doctor Petracchi en otro precedente en el que aseguró:

La Constitución Nacional y el ordenamiento jurídico de que es base normativa deben ser examinadas como un todo coherente y armónico en el cual cada precepto recibe y confiere su inteligencia de y para los demás. De tal modo, ninguno puede ser estudiado aisladamente sino en función del conjunto normativo, es decir, como partes de una estructura sistemática considerada en su totalidad. Esa interpretación debe tener en cuenta, además de la letra, la finalidad perseguida y la dinámica de la realidad, reacia a ser contenida en fórmulas inmutables (csjn Fallos, 312:2192).

No puede soslayarse que la acción civil fue delineada en otro contexto y que durante estos años ha habido una evolución en pos de los derechos de reparación y acceso a la justicia, por lo que deben buscarse soluciones a estas falencias.

En el fallo Cruz Nina, el doctor Hornos fue contundente al explicar qué debe entenderse por ley vigente en el proceso penal, cuando dijo: "el concepto de Ley Vigente abarca a la Constitución Nacional, a los Pactos Internacionales de Derechos Humanos con jerarquía constitucional, los restantes Pactos Internacionales, y al Código Penal y el Código Procesal Penal de la Nación”.

Maier (2012b) señala con claridad que el sistema penal no está organizado como servicio público orientado a la víctima que en el ámbito del derecho privado constituye un problema crítico de acceso a la justicia. Por ello, ofrece una solución que de alguna manera da sustento a la propuesta que formulo en este trabajo, cuando refiere:

Si se liga ciertos progresos normativos con la reparación y un mejor desarrollo procesal de las facultades de la víctima en el procedimiento penal, con un acceso adecuado de la víctima al mundo judicial, universo la mayoría de las veces inescrutable de antemano y motivo de temor para la víctima (curioso: idéntico temor al del imputado; reflejo: temor ciudadano ante los tribunales de justicia), se podría esperar resultados convincentes [...] Entre nosotros, ya han sido dados algunos primeros pasos. Uno de ellos es la llamada delegación de la acción civil, instrumento teórico para corregir el acceso de la víctima a la justicia penal y para lograr que se le repare el daño (Maier, 2012b, p. 632). 
Esto autoriza a pensar en una solución que se adecue a la situación de las víctimas de trata que les facilite el acceso a la reparación. En efecto, en situaciones donde se presentaba un conflicto entre las formas y los derechos, la csjN admitió la relativización de las reglas para no impedir el goce de los derechos reconocidos en normas de jerarquía superior.

El derecho penal no debe ser concebido como manifestación del poder estatal, sino como una instancia de resolución de conflictos sociales en la que la aplicación de soluciones alternativas es posible y donde la víctima tiene un papel preponderante (Maier, 2012a, p. 88).

Todo lo señalado interpela a los operadores jurídicos y obliga a buscar alternativas dentro del derecho procesal que atiendan a las necesidades especiales que presentan las víctimas de trata de personas y que sean más adecuadas a su situación al punto de que les permita una reparación económica. En consecuencia, deben diseñarse propuestas armónicas que respeten los derechos de las víctimas, reconocidos en el derecho internacional de derechos humanos sin violentar el derecho de defensa en juicio.

La pretensión indemnizatoria se verá obstaculizada en los casos de personas que han sido subyugadas al poder del tratante no solo restringiendo su libertad, sino también su autonomía y poder de decisión. Ni siquiera el "rescate" de la víctima logra liberarla del sometimiento, que en la mayoría de los casos muchas veces persiste aun después de la liberación física. ${ }^{8}$

Tal como se indica en la guía elaborada por la PROTEx (2016, p. 16), uno de los mecanismos de control más efectivos es la amenaza de represalias contra ellas o sus seres queridos, lo que obviamente conspira contra las posibilidades de peticionar por reparaciones. Frente este panorama, debe procurarse que el sobreviviente no esté obligado a asumir una persecución para obtener una reparación económica, imponiéndole conseguir el patrocinio de un abogado e impulsando su pretensión, cuando en realidad tiene otras prioridades o simplemente miedo de enfrentar a quien le sometió y vejó. La desigualdad entre ambas partes es evidente y el Estado debe procurarle a la víctima una solución viable para obtener la reparación económica por el daño sufrido.

Por ello, como alternativa se propone que para estos supuestos tan especiales se permita a las personas damnificadas interponer un reclamo de índole civil sin las formalidades impuestas por el proceso penal y al que he llamado: acción civil indemnizatoria in pauperis.

\footnotetext{
8 Para una aproximación a las dificultades de los sobrevivientes de trata de personas para tener acceso a la justicia y el sometimiento que padecen producto de su explotación ver Colombo y Mánģano (2018, p. 90), donde los autores recogen varios testimonios que son esclarecedores.
} 
Para su desarrollo, se parte de la idea del recurso interpuesto en forma pauperis, doctrina elaborada por la csjn que permite la impugnación de una resolución judicial en un proceso penal por parte de una persona imputada sin la debida asistencia letrada, a pesar de que no cumpla con las exigencias formales, dada la situación de desvalimiento en que se encuentra el afectado.

En efecto, la doctrina pauperis establece que, en aplicación al reconocimiento que hacen los artículos 8. 2. h de la CADH y 14. 5 del PIDCP del "derecho de recurrir un fallo ante un juez o tribunal superior", los requisitos formales para la interposición de un recurso no pueden perjudicar a los imputados, titulares del derecho a impugnar una decisión que desatienda su reclamo. Así lo sostuvo en el precedente, Scilingo (csjn, Fallos 320:854), que luego fue reiterado en numerosas oportunidades, en las que dejó en claro que el rigorismo formal debe ceder ante el reclamo informal del interesado que demuestra su voluntad impugnativa y para el caso de que se trate de una persona que carezca del correspondiente amparo y asesoramiento (Palazzi, 2000).

Esta doctrina, que en principio se limitaba a personas detenidas, fue ampliada por la propia CSJN que extendió su aplicación a otros supuestos (por ejemplo, situación de indefensión).

En 2012 amplió aún más el alcance del instituto y admitió un recurso in pauperis en un amparo de salud a quien lo había interpuesto contra la decisión del Tribunal Superior de Justicia provincial que consentía su desafiliación de la obra social por haber cumplido 25 años, a pesar de su delicado estado de salud y su discapacidad (Quinteros, Virginia s/su presentación, 2012). La csjN declaró procedente el recurso y condenó a la obra social a reafiliarla.

Como se ve, este fallo aceptó la interposición de un recurso en una causa no penal sin cumplir con los requisitos formales, pues la actora se encontraba en una condición de vulnerabilidad por ser discapacitada, sin recursos económicos y mujer. Estos presupuestos fueron estimados como fundamento suficiente para autorizar la revisión de una decisión jurisdiccional ante la manifestación informal de impugnar una resolución que le resultaba adversa. Tal como se recordó en el dictamen fiscal, en situaciones delicadas, como las referidas a la salud, la csjn había

interpretado que toca a los jueces buscar soluciones que se avengan con la urgencia que conlleva este tipo de pedidos para lo cual deben encauzar los trámites por las vías expeditivas e impedir que el rigor de las formas pueda conducir a la frustración de derechos que cuentan con tutela constitucional, lo cual se produciría si el reclamo tuviera que aguardar el inicio de un nuevo proceso (csjn, Fallos, 327:2127; 329:4918; 330:4647; 331:563, etc.) 
Con este precedente, queda claro que la posibilidad de flexibilizar las exigencias formales no se reduce a los casos penales, lo que permitiría aplicarse en casos de trata y explotación de personas para que las víctimas reclamen la reparación económica, entendiendo que ellas también son vulnerables y tienen inconvenientes para ejercer su derecho de acceso a la jurisdicción.

Precisamente, el derecho a recurso no se limita a la posibilidad de revisar una sentencia, sino que constituye una de las garantías fundamentales del derecho internacional de derechos humanos. Siguiendo esa línea, el párrafo sexto del artículo 6 del Protocolo de Palermo impone la adopción de medidas para que los sobrevivientes de trata y explotación de personas obtengan una indemnización. Se pone también en juego el derecho reconocido a la víctima de tutela judicial efectiva (artículos 18 de la CN, 8. 2. h de la $\mathrm{CADH}$ y 14.5 del PIDCP) y la idea de concebir al derecho penal como una instancia de solución de conflictos y no únicamente como un ejercicio del poder punitivo del Estado.

En efecto, el derecho a una tutela judicial efectiva comprende el derecho de acceso a la jurisdicción. La Comisión Interamericana de Derechos Humanos (CIDH, 2007) elaboró un informe donde recalcó que las acciones judiciales fueron pensadas para la protección de los derechos civiles y políticos "clásicos" y, por tanto, se han establecido procedimientos sencillos y rápidos para amparar derechos en casos graves y urgentes, dejando de lado otro tipo de derechos. Por ende, advirtió la existencia de inconvenientes para ejercitar dichas acciones al excluir la tutela de derechos de los no considerados fundamentales o por estipular requerimientos excesivos para su admisión. Concluye que el derecho de tutela judicial efectiva requiere de procedimientos judiciales que no "presenten condiciones u obstáculos que le quiten efectividad para cumplir con los fines para los que fueron previstos".

Sentado ello, se cuenta con los fundamentos jurídicos y doctrinarios para aceptar un reclamo indemnizatorio en forma pauperis, resta determinar cómo se podría llevar adelante esa acción.

\subsection{Método para interponer la acción en forma pauperis o in pauperis}

Como ya se ha mencionado, quienes han sobrevivido a la trata de personas por las condiciones personales, por el delito que padecieron y por el mismo contacto con el sistema de justicia pertenecen a un grupo en situación de vulnerabilidad para el que, en la práctica, no es posible asumir un rol activo en el proceso penal -mucho menos en el fuero civil-, con el propósito de obtener una indemnización. Por ello, es responsabilidad del Estado encontrar la manera de superar los obstáculos que se presentan procesalmente al disponer requisitos extremadamente formales. 
Se reconoce que el primer mecanismo para hacerlo sería mediante la sanción de una ley, pero hasta que ello ocurra y para no dejar desamparadas a quienes hoy son víctimas podría crearse pretorianamente una vía alternativa. Resulta evidente que las vías procesales actuales son inoperantes $\mathrm{y}$, por tanto, deben ser adecuadas para posibilitar un real acceso a la justicia a fin de obtener una satisfacción a sus necesidades económicas.

En ese sentido, cada uno de los requisitos exigidos para entablar la pretensión resarcitoria podría ser reemplazado por un mecanismo menos formal, pero que no signifique violentar el derecho de defensa del demandado. Por ejemplo, el requisito de manifestar expresamente la voluntad de ejercer la pretensión resarcitoria podría verse satisfecho con la suscripción de un acta o protocolo en el que la víctima exprese claramente aquella decisión, en la primera oportunidad posible.

Por consiguiente, sería necesario tomar el recaudo de que durante el proceso, el titular de la acción exprese su voluntad de obtener una indemnización y se fije un monto para determinar la pretensión (aunque, como ya vimos, en virtud del artículo 29. 2 del CPN el juez posee facultades amplias para fijar la indemnización cuando no haya plena prueba).

Luego, la determinación de la relación causal entre el daño producido y el hecho que lo provoca puede verse realizada en el requerimiento de elevación a juicio. ${ }^{9}$

Para asegurar la inviolabilidad de la defensa en juicio y evitar que una sentencia indemnizatoria sea sorpresiva para el legitimado pasivo, la pretensión resarcitoria podría ser promovida desde la Fiscalía, quien está habilitada para intervenir en aquellos conflictos en los que esté afectado gravemente el acceso a la justicia por la especial vulnerabilidad de una de las partes o la notoria asimetría entre ellas (Ley 27.148, artículo 2, inciso e).

De esa manera, podría intentarse una reparación en la que la concreción de la pretensión en los casos de trata de personas y delitos conexos la realice el fiscal, para lo que sería necesario que, sin demasiadas formalidades:

- El consentimiento de la persona afectada, por lo que se deberá procurar que en la primera oportunidad posible y cuando se estime oportuno se deje constancia de la decisión de pretender un resarcimiento económico por el daño sufrido.

- Una vez expresada la voluntad de la víctima de obtener una indemnización, el fiscal en el requerimiento de elevación a juicio (o formulación de la acusación) incluya un apartado donde se indique el monto aproximado que se

9 De acuerdo con el CPPF (Ley 27.063), esto podría satisfacerse al momento de formular la acusación en los términos del artículo 274. 
reclama, con indicación de los rubros que se pretenden cubrir. La descripción de los hechos que dieron origen al daño y el vínculo entre la víctima y el suceso antijurídico estaría correctamente acreditado con la descripción de los hechos que se hace en el requerimiento y su valoración.

\section{Recursos económicos para solventar las reparaciones}

\subsection{Recuperación de activos en trata de personas y delitos conexos}

En primer término, se ha de aclarar que las reparaciones económicas a las que vengo haciendo mención en este trabajo no están concebidas para ser asumidas por el Estado, en lo que podría pensarse como una suerte de indemnización general, sino que aquellas determinadas judicialmente deberán ser solventadas, en principio, por los bienes de los responsables de haber cometido el delito o de quienes, sin haber sido considerados autores o partícipes (sin haber sido imputados siquiera), se beneficiaron de la actividad delictiva.

Para ello, es fundamental que durante la sustanciación del proceso se realice una investigación patrimonial que identifique los activos que servirán para hacer frente a las reparaciones que se determinen, tal como establece el párrafo segundo del artículo 28 de la Ley 26.364 (incorporado por Ley 27.508), que obliga a los magistrados y funcionarios del poder judicial y MPF a practicar dicha investigación en la primera oportunidad posible.

La legislación argentina, en línea con los compromisos internacionales asumidos por el país mediante la suscripción de la CNUDOT, otorga prioridad absoluta a los derechos de restitución y reparación económica de las víctimas del caso respecto del decomiso y de la pena de multa (CP artículos 23,29 y 30 ). Precisamente, el artículo 14. 2 de dicha convención internacional estipula la prioridad de la devolución del producto de los delitos contenidos referidos allí para indemnizar a las víctimas. El artículo $23 \mathrm{CP}$ dispone que el producto o provecho del delito será decomisado en favor del Estado, salvo que previamente corresponda satisfacer los derechos de restitución o indemnización del damnificado.

Para el caso de la trata de personas y delitos conexos, el citado artículo 23, párrafo sexto CP determina que también se decomisarán los muebles o inmuebles donde se mantuvo a la víctima privada de su libertad o donde fue objeto de explotación. Además, los párrafos tercero y cuarto del artículo $23 \mathrm{CP}$ extienden el alcance del decomiso de las ganancias que son producto o provecho del delito a terceros no condenados: (a) personas de existencia ideal que se hubieren beneficiado del producto o provecho del delito cometido por sus órganos, miembros y administradores, y (b) quienes se hubieren beneficiado del producto o provecho del delito a 
título gratuito. El artículo 32 de la CPN también autoriza ir en contra de terceros para las reparaciones si estos obtuvieron un beneficio económico del delito.

\subsection{Función subsidiaria del decomiso}

De lo expuesto en los apartados anteriores, ha quedado claro que las reparaciones económicas que se fijen en cada caso tendrán privilegio por sobre los decomisos que dispongan, de modo que, si hubiera víctimas identificadas, los importes correspondientes a las reparaciones deberán asegurarse con los bienes, ya sean producto o provecho del delito o su instrumento, en virtud del orden de prioridades que establecen en forma expresa los artículos 30 del CP y 14. 2. de la CNUDOT que expresamente disponen que las indemnizaciones y devolución del producto a sus legítimos propietarios (restitución) tienen consideración prioritaria frente a su decomiso.

Entonces, si los bienes de los condenados no fueren suficientes para cubrir todas sus responsabilidades pecuniarias, estos se destinarán en forma preferente a reparar los daños causados a las víctimas del delito. Así lo ha reconocido la Sala II de la CFCP en el citado fallo Montoya, cuando estimó que el Tribunal Oral Federal había aplicado

erróneamente el artículo $23 \mathrm{cp}$ y favoreció el patrimonio de entidades estatales - entre otros, la Corte Suprema de Justicia de la Nación - por sobre la indemnización correspondiente a las víctimas y el destino asignado legalmente a los bienes sujetos a decomiso. De tal suerte, omitió atenerse a un deber que es primario y básico en la actuación judicial: reparar a la víctima antes que beneficiar al propio Estado.

En otro antecedente, la misma Sala había considerado:

a distancia de la ley, se evidencia una situación paradójica, donde se da preeminencia a aumentar el patrimonio estatal en detrimento del derecho de las víctimas a ser indemnizadas por los autores responsables. En efecto, resulta plausible que el decomiso en favor del Estado determine la insolvencia de los encartados, quienes pueden no disponer de patrimonio para cumplir con las reparaciones (Quiroga, José Luis s/ recurso de casación, 2017).

\subsection{Fondo fiduciario Ley $\mathbf{2 6 . 3 3 4}$}

La Ley 26.364 determina que los bienes decomisados en estos casos se destinarán a un fondo de asistencia directa a las víctimas administrado por el "Consejo Federal para la Lucha contra la Trata y Explotación de Personas y para la Protección y Asistencia a las Víctimas" (artículo 27). Esta norma fue complementada con la recientemente 
sancionada Ley 27.508 (y su decreto reglamentario 844/2019) que crea un fondo fiduciario que administrará el dinero en efectivo y el producido de la venta de los bienes decomisados en el marco de los procesos judiciales por trata y explotación de personas, así como del lavado de activos provenientes de dichos delitos, ${ }^{10}$ con sentencia firme o cuando, sin estar firme, el juez de la causa autorice la venta.

Además, esta norma define la prioridad en el destino de los bienes decomisados y estableció la responsabilidad solidaria del fondo para responder frente a los sobrevivientes del delito de trata y explotación de personas por las restituciones y reparaciones económicas que, luego de ser ordenadas judicialmente, no pudieron ser satisfechas con los bienes del condenado (artículo 3).

\section{Conclusiones}

La comunidad internacional ha reconocido a través de diversos instrumentos la obligación de reparar económicamente por el daño sufrido como consecuencia de un delito, especialmente, cuando se trata de una grave violación de derechos humanos.

En Argentina, si bien los códigos procesales del fuero civil y penal regulan la posibilidad de formular un reclamo por los daños y perjuicios provocados por el delito, lo cierto es que este tipo de demanda no tiene en consideración las especiales dificultades que deben atravesar las víctimas de trata de personas, suscitadas por el delito que padecieron, por su situación de vulnerabilidad y las vicisitudes propias de su contacto con el sistema penal, que muchas veces acentúa aquella condición. Estas circunstancias hacen que, en la práctica, sea imposible que quienes fueron atravesados por este delito puedan entablar un reclamo indemnizatorio.

Así se vulneran sus derechos a la reparación y de acceso a la jurisdicción, ambos con reconocimiento internacional. Al respecto, en el caso Trabajadores de la Hacienda Brasil Verde, la Corte IDH fue contundente al sostener que no contar con un procedimiento adecuado que permita acceder a una reparación económica en un caso de trata de personas, era violatorio de los derechos reconocidos en los artículos 8 y 25 de la CADH. No quedan dudas, entonces, de que ante la situación de vulnerabilidad de los sobrevivientes, el Estado es responsable de proveer un recurso sencillo y efectivo para la protección de sus derechos.

10 Resulta importante la incorporación del decomiso de bienes provenientes del delito de lavado de activos, pues como bien señala Aboso (2013), los enormes beneficios económicos obtenidos a partir de explotación de las personas son incorporados al mercado y transformados o convertidos para ocultar su origen ilícito (p. 64). 
Por ello, es inaceptable que quienes sufrieron tan aberrante delito no puedan contar con la reparación económica que les posibilite, de alguna manera, recuperar la autodeterminación que les fue arrebatada. La iniquidad de esta situación debe interpelar a los funcionarios judiciales y magistrados ante una legislación procesal que constituye una privación de derechos contraria al derecho internacional de los derechos humanos.

En este contexto, formulé como propuesta la implementación de un mecanismo sencillo, en el marco de un proceso penal, que flexibilice las formas y requisitos a efectos de ofrecer una solución sencilla y compatible con los estándares de derechos humanos para que los sobrevivientes en situación de vulnerabilidad obtengan una reparación económica integral. Basado en la doctrina desarrollada por la csjN para admitir determinados recursos in pauperis, a este procedimiento lo he denominado "acción civil indemnizatoria in pauperis". Se trata de una herramienta asequible que sería llevada adelante por el MPF, a instancias de la víctima, concomitantemente con la acción penal y despojada de las formalidades exigidas por el ordenamiento procesal penal en el que la acusación sería el momento en el que se precise la pretensión resarcitoria.

Esta idea poco convencional fue receptada por la csjn que aceptó la desacralización del proceso con el propósito de asegurar el acceso a la justicia. En definitiva, la "acción civil indemnizatoria en forma pauperis" sería una alternativa que, al desacralizar las formas, confiere a las víctimas una vía de acceso a la jurisdicción, sin arriesgar su integridad física o la de sus seres queridos. Esta solución se enmarca en lo que se ha denominado "perspectiva de vulnerabilidad", que no es otra cosa que un enfoque que necesariamente deben tener los funcionarios judiciales y magistrados para comprender la realidad de quienes entran en contacto con el sistema penal y así adoptar decisiones que contemplen soluciones acordes a dichas condiciones, aunque ello signifique relativizar ciertas formalidades cuyo rigorismo termina por configurar una violación de derechos humanos.

Ante la carencia en el ordenamiento interno argentino de una herramienta para cumplir con las obligaciones internacionales de reparar los daños ocasionados por las violaciones a los derechos humanos, se cuenta con la base legal y dogmática que sustenta la aplicación de la acción civil in pauperis, que se erige como una alternativa viable hasta tanto se implemente un mecanismo legal compatible con los estándares internacionales. 


\section{Referencias}

Aboso, G. E. (2013). Trata de personas. La criminalidad organizada en la explotación laboral y sexual. Editorial B de F.

Alto Comisionado de las Naciones Unidas para los Derechos Humanos [ACNUDH]. (1981). Convención sobre la eliminación de todas las formas de discriminación contra la mujer. https://www.ohchr.org/Documents/ProfessionalInterest/cedaw_SP.pdf

Alto Comisionado de las Naciones Unidas para los Derechos Humanos [ACNUDH]. (1987). Convención contra la Tortura y otros Tratos o Penas Crueles, Inhumanos o Degradantes. https://www.ohchr.org/Documents/ProfessionalInterest/cat_SP.pdf

Alto Comisionado de las Naciones Unidas para los Derechos Humanos [ACNUDH]. (2014). Los derechos humanos y la trata de personas 36. https://www.ohchr. org/Documents/Publications/FS36_sp.pdf

Asamblea General, Organización de las Naciones Unidas. (1966). Pacto Internacional de Derechos Civiles y Políticos. https://www.ohchr.org/Documents/ ProfessionalInterest/ccpr_SP.pdf

Asamblea General, Organización de las Naciones Unidas. (2005). Principios y directrices básicos sobre el derecho de las víctimas de violaciones manifiestas de las normas internacionales de derechos humanos y de violaciones graves del derecho internacional humanitario a interponer recursos y obtener reparaciones. https://www.ohchr.org/sp/professionalinterest/pages/remedyandreparation. aspx

Asamblea General de la Organización de las Naciones Unidas [AGNU]. (2006). Resolución 60/147. Principios y directrices básicos sobre el derecho de las víctimas de violaciones manifiestas de las normas internacionales de derechos humanos $y$ de violaciones graves del derecho internacional humanitario a interponer recursos y obtener reparaciones. https://legal.un.org/avl/pdf/ha/ ga_60-147/ga_60-147_ph_s.pdf

Asamblea General, Organización de las Naciones Unidas [AGNU]. (2011). Promoción y protección de todos los derechos humanos, civiles, políticos, económicos, sociales y culturales, incluido el derecho al desarrollo. Informe de la Relatora Especial sobre la trata de personas, especialmente mujeres y niños, la Sra. Joy Ngozi Ezeilo. A/HRC/17/35. https://undocs.org/sp/A/HRC/17/35 
Cámara Federal de Casación Penal [CFCP], Sala I, Argentina. Cruz Nina, Julio César; Huarina Chambi, Silvia s/ trata de personas (30 de diciembre de 2016). https:// cdh.defensoria.org.ar/normativa/cruz-nina-julio-cesar-huarina-chambi-silva-s-trata-de-personas/

Cámara Federal de Casación Penal [CFCP], Sala II, Argentina. Quiroga, José Luis s/ recurso de casación (6 de abril de 2017).

Cámara Federal de Casación Penal [CFCP], Sala II, Argentina. Montoya, Pedro y otras s/ recurso de Casación (12 de abril de 2018). https://cdh.defensoria. org.ar/normativa/montoya-pedro-eduardo-y-otras-s-recurso-de-casacion/

Colombo, M., \& Mángano, M.A. (2018) Breves notas sobre la reparación a las víctimas de trata de personas a través del recupero de activos. En M. V. Rodríguez (Comp.), Reparación integral: un derecho de las víctimas de trata de persona (pp. 85-100). Defensoría General de la Nación de Argentina.

Comisión Interamericana de Derechos Humanos [CIDH]. (2007). El Acceso a la justicia como garantía de los derechos económicos, sociales y culturales: estudio de los estándares fijados por el sistema interamericano de derechos humanos. OEA/Ser.L/V/II.129. http://www.cidh.org/countryrep/AccesoDESC07sp/Accesodesci-ii.sp.htm

Consejo Económico y Social de la Organización de las Naciones Unidas [ECOsoc]. (2002). Principios y directrices recomendados sobre los derechos humanos y la trata de personas. E/2002/68/Add.1. https://undocs.org/E/2002/68/Add.1

Consejo de Europa. (2005) Convenio del Consejo de Europa sobre la trata de seres humanos. https://www.idhc.org/img/butlletins/files/ConveniodeConsejoEuropaTrata\%281\%29.pdf

Consejo de Europa. (1998). Convenio Europeo para la Protección de los Derechos Humanos y de las Libertades Fundamentales.

Corte Interamericana de Derechos Humanos [Corte IDH]. Caso Velásquez Rodríguez c. Honduras. Reparaciones y costas (21 de julio de 1989). https://www. corteidh.or.cr/docs/casos/articulos/seriec_07_esp.pdf

Corte Interamericana de Derechos Humanos [Corte IDH]. Caso Trabajadores de la Hacienda Brasil Verde c. Brasil. Excepciones preliminares, fondo, reparaciones y costas (20 de octubre de 2016). https://www.corteidh.or.cr/docs/casos/ articulos/seriec_318_esp.pdf 
Corte Interamericana de Derechos Humanos [Corte IDH]. González, y otras (Campo Algodonero) c. México (16 de noviembre de 2009).

Corte Suprema de Justicia de la Nación Argentina. Fallos, 138:157. http://sjservicios. csjn.gov.ar/sj/tomosFallos.do?method=verTomoPagina\&tomo=138\&pagina $=157 \#$ page $=157$

CSJN Fallos, 312:2192. https://sjconsulta.csjn.gov.ar/sjconsulta/documentos/verDocumentoSumario.html?idDocumentoSumario $=1481$

CSJN. Scilingo, Adolfo [Fallos 320:854] https://sjconsulta.csjn.gov.ar/sjconsulta/ documentos/verDocumentoSumario.html?idDocumentoSumario=6191

CSJN [23 de febrero de 2012]. Quinteros, Virginia s/su presentación. Q.43.XLV. Recurso de hecho. https://sjconsulta.csjn.gov.ar/sjconsulta/documentos/ verDocumentoById.html?idDocumento=129331 y https://www.mpf.gov. ar/dictamenes///2011/beiro/4-abril/quinteros_virginia_q_43_1_xlv.pdf

D’Alessio, A. J. (2005). Código Penal comentado y anotado parte general. La Ley Argentina.

Declaración sobre los principios fundamentales de justicia para las víctimas de delitos y del abuso de poder.

Declaración Universal de Derechos Humanos.

Estatuto de Roma de la Corte Penal Internacional.

Garantías para el acceso a la justicia, el rol de los defensores públicos oficiales .

Guías de Santiago sobre protección de víctimas-testigos (XVI Asamblea General Ordinaria de la Asociación Ibero Americana de Ministerios Públicos [AIAMP], el 9 y 10 de julio de 2008).

Gutiérrez Rodríguez, M. (2017). Las víctimas ante la Corte Penal Internacional: ¿efectiva realización de los derechos de participación y reparación? En E. Maculan \& A. Gil Gil (Coords.), La influencia de las víctimas en el tratamiento jurídico de la violencia colectiva (pp. 47-79). Dykinson.

Maier, J. (2012a). Derecho procesal penal I. Editores del Puerto.

Maier, J. (2012b). Derecho procesal penal II. Editores del Puerto. 
Oficina contra la Droga y el Delito, Organización de las Naciones Unidas. (2004). Convención de las Naciones Unidas contra la Delincuencia Organizada Trasnacional (CNUDOT) y sus protocolos. https://www.unodc.org/documents/ treaties/UNTOC/Publications/TOC\%20Convention/TOCebook-s.pdf

Oficina de la Droga y el Delito, Organización de las Naciones Unidas [UNODC]. (2006). Manual sobre programas de justicia restaurativa. Serie de Manuales sobre Justicia Penal. https://www.unodc.org/documents/justice-and-prison-reform/Manual_sobre_programas_de_justicia_restaurativa.pdf

Organización de los Estados Americanos [oEA]. (1969). Convención Americana sobre Derechos Humanos (Pacto de San José de Costa Rica). https://www.oas. org/dil/esp/tratados_B-32_Convencion_Americana_sobre_Derechos_Humanos.pdf

Organización de los Estados Americanos [OEA]. Protocolo adicional a la Convención Americana sobre Derechos Humanos en materia de derechos económicos, sociales y culturales "Protocolo de San Salvador". https://www.oas.org/juridico/spanish/tratados/a-52.html

Organización de los Estados Americanos [oEA]. (s. f.). Convención Interamericana para Prevenir, Sancionar y Erradicar la Violencia contra la Mujer "Convención de Belem do Pará". https://www.oas.org/juridico/spanish/tratados/a-61.html

ONU Mujeres. (s. f.). Preguntas frecuentes: Tipos de violencia contra las mujeres $y$ las niñas. https://www.unwomen.org/es/what-we-do/ending-violence-against-women/faqs/types-of-violence

Palazzi, P. (2000). El derecho a una defensa eficaz en el proceso penal. Revista el Derecho, 164, 624.

Pozzo, M. (2012). Garantía para el acceso a la justicia de los sectores más vulnerables. Empoderamiento de los Defensores Públicos Oficiales. Revista de Derecho Penal y Criminología, 2(6), 159-162.

Procuraduría de Trata y Explotación de Personas, Argentina. (2016). El testimonio de la víctima de trata de personas. Herramientas útiles para la recepción y valoración de la declaración testimonial. https://www.fiscales.gob.ar/wp-content/uploads/2016/07/Protex-Testimonio-V\%C3\%ADctima-Trata.pdf 
Requena Espada, L., Giménez-Salinas Framis, A., \& de Juan Espinosa, M. (2012). Estudiar la trata de personas. Problemas metodológicos y propuestas para su resolución. Revista Electrónica de Ciencia Penal y Criminología, (14-13), 13:1-13:28. http://criminet.ugr.es/recpc/14/recpc14-13.pdf

Tribunal Oral en lo Criminal Federal de Tierra del Fuego, Argentina. Montoya, Pedro y otros s/ inf. art. 145 bis -conforme Ley 26.482 (30 de noviembre, 2016).

Tribunal Oral Federal 4, Argentina. Tomasi, Silvio Ángel y otros s/trata de personas (26 de septiembre, 2019). CFP 6013/2013/TO1. 